\title{
Suppression of Mutual Coupling Between Two Microstrip Patch Antennas using a Sophisticated Non-Linear DGS Structure for High Frequency Wave Applications
}

Submitted: 02/09/2017

Revised: $29 / 10 / 2017$

Accepted: 01/11/2017

\author{
Lavesh Gupta* \\ Arun Dev Dhar Dwivedi**
}

\begin{abstract}
Purpose - If the two or more than two antennas are present in the antenna array, the mutual coupling between them becomes a critical issue to deal with. At microwave frequency, microstrip design is often used as a transmission line because of its good performance in transferring the energy and microwave signals. Most commonly used microstrip antenna has similar structure as that of the microstrip line. On one side of dielectric substrate layer, is an extremely thin layer of conductor that forms the radiating elements and on bottom side is the ground plane made up of metallic material. Our main motive is to maintain mutual coupling suppressing structure to its simplest form.

Methodology/approach/design - We therefore use a Defected Ground Structure (DGS), which greatly decreases the mutual coupling between the two antennas, thus enhancing the performance of the antenna array.

Findings - The introduction of the DGS does not affect the characteristics of antenna array system. The Simulation is done using CST (Computer Simulation Technology) software and the results are tested using Vector Network Analyzer. Both the simulated and measured results are in good agreement. The coupling has been reduced from -22 to $37 \mathrm{~dB}$. The recent boom in wireless industry has led to the demand for the multiband antennas.
\end{abstract}

Keywords: Antenna Array System, Defected Ground Structure (DGS), Microstrip Patch Antennas, Mutual Coupling Reduction, CST Antenna Full-Wave Electromagnetic Simulator.

\section{Introduction}

When a number of antenna elements are placed into an array formation, the mutual coupling between the antenna array elements must be taken into the account. The Microstrip Patch Antennas are used for sending the onboard

\footnotetext{
*Ph.D. Research Scholar, Department of Electronics \& Communication Engineering, Poornima University, Jaipur, Rajasthan, India. Email: laveshgupta5@ gmail.com.

**Professor, Department of Electrical and Electronics Engineering, Poornima University, Jaipur, Rajasthan, India. Email: adddwivedi@gmail.com.

GUPTA, L.; DWIVEDI, A. D. D. Suppression of Mutual Coupling Between Two Microstrip Patch Antennas using a Sophisticated Non-Linear DGS Structure for High Frequency Wave-Applications. The Law, State and Telecommunications Review, Brasilia, v. 10, n. 1, p. 161-184, May 2018.

[DOI: https://doi.org/10.26512/lstr.v10i1.21505]
} 
parameters to ground surface under different operational conditions. The main motive is to maintain mutual coupling suppressing structure to its simplest form while providing the high amount of reduction in the mutual coupling of patch antenna elements [1-3].

The idea is to use the Defected Ground Structure (DGS) placed at bottom of substrate. It highly reduces the mutual coupling between antenna elements, thus enhancing the antenna design performance. The introduction of the DGS doesn't affect the other characteristics of antenna array [4]. The DGS \& normal patch antenna array design is simulated using CST (Computer Simulation Technology) antenna simulator software \& tested in the lab using Vectornetwork-analyzer. Once an antenna design is finalized, the operational characteristics of the antenna design system remains unchanged, during its use [5].

The most considerable advantage of the microstrip line is that it doesn't generate as much parasitic capacitance and inductances, as the lumped elements does. Furthermore, as compared with other kind of transmission line, the stripline and microstrip designs are much easier \& cheaper to fabricate and easy to connect to the surface mounted components. In prior works, the H-shaped, Ushaped and other cross-sectional structures were used for mutual coupling reduction [2, 9]. At microwave frequency, microstrip is often used as transmission line because of its great performance in transfer of microwave signals $[1,2,5]$.

The commonly used microstrip patch antenna has the similar structure as that of microstrip line. The general shapes of conductor are taken such as square, rectangle, triangles and circles for easy analysis and fabrication considerations. The operating frequency of the microstrip antennas generally ranges from 1-50 GHz. A single patch antenna provides high directive gain. It is comparatively easier to place an array of patches over a single large substrate, using the lithographic techniques $[1,6,7]$. From a system stand point, antennas have been viewed as static and passive devices with the time constant characteristics. Once an antenna design is finalized, the operational characteristic of antenna design remains unchanged during its use. The recent boom in wireless communication industry, especially in field of cellular telephony and wireless data communication, has lead to the demand for the multiband antennas [1]. Reconfigurable multiband patch antennas are attractive for various military and other commercial operations where it is necessary to have single antenna which can be dynamically reconfigured to transmit and receive the multiple frequency of bands. This common aperture antenna having multiple frequency bands, received a great attention in recent years for their good properties of adapting with change in system requirements [8]. 
In this research paper, analysis of mutual coupling between (b/w) two microstrip patch antennas and the suppression of mutual coupling between microstrip patch antenna elements has been investigated and simulated using CST (Computer Simulation Technology) Antenna Simulator Software [4, 9]. The results are tested using vector-network-analyzer. To make the proposed antenna, two microstrip patch elements are incorporated in the same substrate. The simulated \& measured results are well-matched [9]. The different types of antenna parameters such as return loss, radiation pattern, radiation efficiency, antenna efficiency, $\mathrm{s}_{11} \& \mathrm{~s}_{21}$ parameters are also investigated in this array design $[2,4]$.

\section{Designing of 2.4 GHz Antenna Array}

For designing, we start with the conventional patch antenna and calculate its length and width at $2.4 \mathrm{GHZ}$ [10]. The patch antenna is connected to the feed line through quarter-wave transformer for impedance-matching $b / w$ the patch $\&$ the feed-line [1]. The structure of patch antenna is shown below in figure 1 . The designed values are as follows $[2,4]$.

- Width of both the input feed lines $=3.05 \mathrm{~mm}$.

- Length of both the input feed lines $=12 \mathrm{~mm}$.

- Width of both impedance matching quarter wave transformers (Tx-1 and $\mathrm{Tx}-2)=1 \mathrm{~mm}$.

- $\quad$ Length of both impedance matching quarter wave transformers $=17.52$ $\mathrm{mm}$.

- Width of both microstrip patch antennas $=40 \mathrm{~mm}$.

- Length of both the patch antennas $=28.2 \mathrm{~mm}[2,5]$.

\section{PATCH}

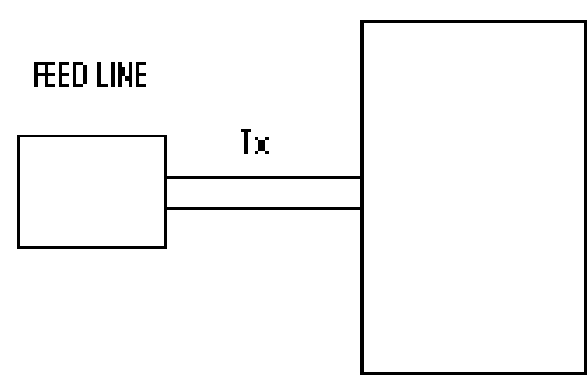

Figure 1 - Compact Structure of a Patch Antenna [1, 2, 4, 6-10] 
The length and width of the feed lines, patch antennas and quarter wave transformers are given. To design the proposed antenna, we need to know the coordinates of feed lines, patch antennas and quarter wave transformers. The respective coordinates of feed lines, patches and impedance matching quarter wave transformers are given below in the following table:

\begin{tabular}{|c|c|c|c|c|c|c|}
\hline $\begin{array}{l}\text { Coordinates } \\
\text { of Array } \\
\text { Elements. }\end{array}$ & $\begin{array}{c}\text { Feed } \\
\text { Line-1 }\end{array}$ & Tx-1 & Patch-1 & $\begin{array}{c}\text { Feed } \\
\text { Line- 2 }\end{array}$ & Tx-2 & Patch-2 \\
\hline $\begin{array}{c}\text { (X) - } \\
\text { coordinate }\end{array}$ & 0 & 10 & 27.52 & 138 & 120.48 & 92.28 \\
\hline $\begin{array}{c}\text { (Y) - } \\
\text { coordinate }\end{array}$ & 73.47 & 74.5 & 55.1 & 73.47 & 74.5 & 55 \\
\hline
\end{tabular}

Table 1 - Co-ord. of Microstrip Patch Elements [1, 2, 5, 7]

\section{Microstrip Patch Antenna Array}

The Microstrip Patch Antenna consists of a radiating patch on one side and the ground plane on other side of the substrate. The two single band patch antennas are printed on the substrate, as shown in figure 2 [1]. The patch antenna is connected to the feed line through quarter-wave transformer for impedance-matching $\mathrm{b} / \mathrm{w}$ the patch $\&$ the feed-line [1].

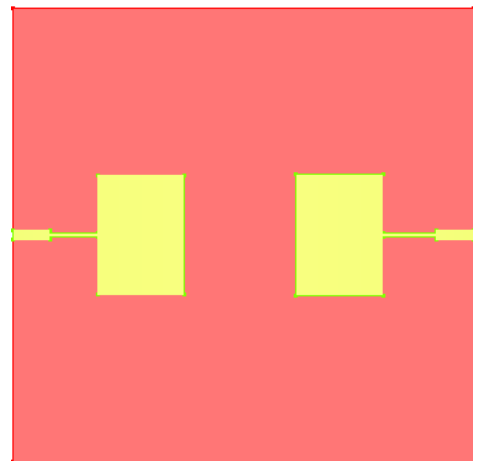

Figure 2 - Microstrip Patch Array [1, 2, 4, 11, 12, 13]

The square shaped dielectric substrate of size $150 \times 150$ sq. $\mathrm{mm}$ is taken, which has a permittivity (dielectric constant) of 4.4 and a thickness of $1.60 \mathrm{~mm}$. The dimensions of both the patches are $28.2 \mathrm{~mm} \times 40 \mathrm{~mm}$ and the distance between both the patch antennas is $34 \mathrm{~mm}[2,4]$. 
The optimized length of feed line is $12 \mathrm{~mm}$ and its width is about 3.05 $\mathrm{mm}$. The impedance matching transformer has an impedance of $70 \mathrm{ohms}$. Its length is $17.52 \mathrm{~mm}$ and optimized width is $1.0 \mathrm{~mm}$. The work of impedance matching quarter wave transformer is to match the impedances between the feed lines and microstrip patch antenna elements precisely in the array design $[2,4]$. The feed line is attached to a 50 ohms connector. Both the feed lines are fed individually. The patch element array has a ground plane, dielectric substrate and two rectangular antenna patches [1]. In simulation of microstrip patch antenna elements, the meshing of $20 \%$ has been performed. The gain analysis between the two patch antenna elements and deduction of mutual coupling between two microstrip patch antennas has been properly investigated through CST Software [9].

The Resonance Frequency of the designed antenna array is 2.4 GHZ. Both the patch antennas have a return loss of around $-16 \mathrm{~dB}$ each. FR-4 is the dielectric substrate, used in manufacturing of proposed microstrip patch design structure. The negative value of return loss shows clearly that this antenna does not have great losses, during transmission of signals through antenna array system $[2,4,5,12]$.

\section{Suppression of Mutual Coupling by Using Defected Ground Structure (DGS)}

If two microstrip antennas are placed in front of each other, the degradation of performance is shown by both the antennas. To avoid this degradation, a defected ground structure is placed at the ground plane of substrate $[4,5,12]$. This array size is suitable to obtain gain b/w $4-9 \mathrm{~dB}$ in the designed system. An I-shaped DGS is used in this system to reduce the coupling in the designed antenna array system, which is shown below in figure 3 . The three lines- LINE 1, LINE 2 and LINE 3 form the desired DGS section [4, 5, 10].

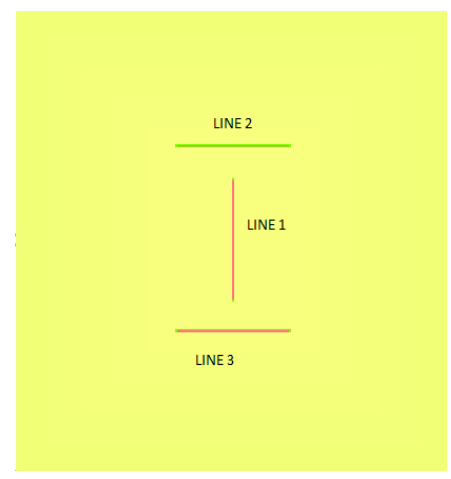

Figure 3 - Defected Ground Plane [1, 2, 4, 9, 14]

GUPTA, L.; DWIVEDI, A. D. D. Suppression of Mutual Coupling Between Two Microstrip Patch Antennas using a Sophisticated Non-Linear DGS Structure for High Frequency Wave-Applications. The Law, State and Telecommunications Review, Brasilia, v. 10, n. 1, p. 161-184, May 2018. 
After using defected ground structure technique, the high radiation efficiency of $94 \%$ has been obtained. Also, the high antenna efficiency of $90 \%$ is obtained. In this paper, the mutual coupling between the patch antenna elements is reduced by using defected ground section, in which the copper is etched/removed out from the back plane of the dielectric substrate, using the process of etching in the array design $[4,5,12]$.

In this proposed DGS structure, the three-line patches are formed in ground plane of the substrate namely LINE 1, LINE 2 and LINE 3. The LINE 1 patch has dimension of $1 \mathrm{~mm} \times 40 \mathrm{~mm}$. On the other side, LINE 2 and LINE 3 patches are having the equal dimensions of $40 \mathrm{~mm} \times 1 \mathrm{~mm}$ in the designed DGS structure [4].

DGS is defined as an etched periodic/non-periodic cascaded configuration defect in the ground of a planar transmission line (e.g., microstrip, coplanar, co-axial and conductor backed coplanar wave guide) that disturbs the shield current distribution in the ground plane, causing a defect in its surface [4, $5,12]$.

The disturbance will change the characteristics of transmission line like capacitance and inductance. In a word, any defect etched in ground plane of microstrip design can give rise to the increasing effective capacitance and inductance. DGS adds an extra degree of freedom in the microwave circuit design and opens the door to a wide range of applications [10].

In the following years, a lot of novel DGS sections were proposed and they had become one of the most interesting areas of research, owing to their extensive applicability in microwave circuit designs [4].

The parameters of equivalent circuit models of DGSs were researched and utilized to design the planar circuits. Until recently, the microstrip filter designing was being done with the full metallic ground plane, present on one side of substrate. Many passive and active microwave and millimeter devices have been made to suppress harmonic factors and realize the compact physical dimensions of the circuits, for the design, flow of circuits with the use of simple DGS [4].

\section{Methodology \& Materials Used}

In order to realize a compact structure at $2.4 \mathrm{GHZ}$ frequency, dual polarized microstrip patch antennas are printed over FR 4 substrate, having a thickness of $1.60 \mathrm{~mm}$ and a dielectric permittivity of $4.4[2,4,10]$.

The microstrip patch antenna array design must be compact with maximum authorized surface area of $150 \times 150 \mathrm{sq}$. $\mathrm{mm}$. The effective dielectric constant of FR-4 substrate comes out to be 4.085 on the calculation [2]. 
Between two microstrip patch antennas, printed over high permittivity substrate, the mutual coupling is high. Hence, to improve isolation between the patch antenna elements, we incorporate ground plane by the use of defected ground structure [4]. The process of fabrication of the antenna array system includes the various steps of the photolithographic techniques in the designing of the patch antenna array, which are discussed below in great detail using a precise and stepwise flowchart sequence [1, 10-20]:

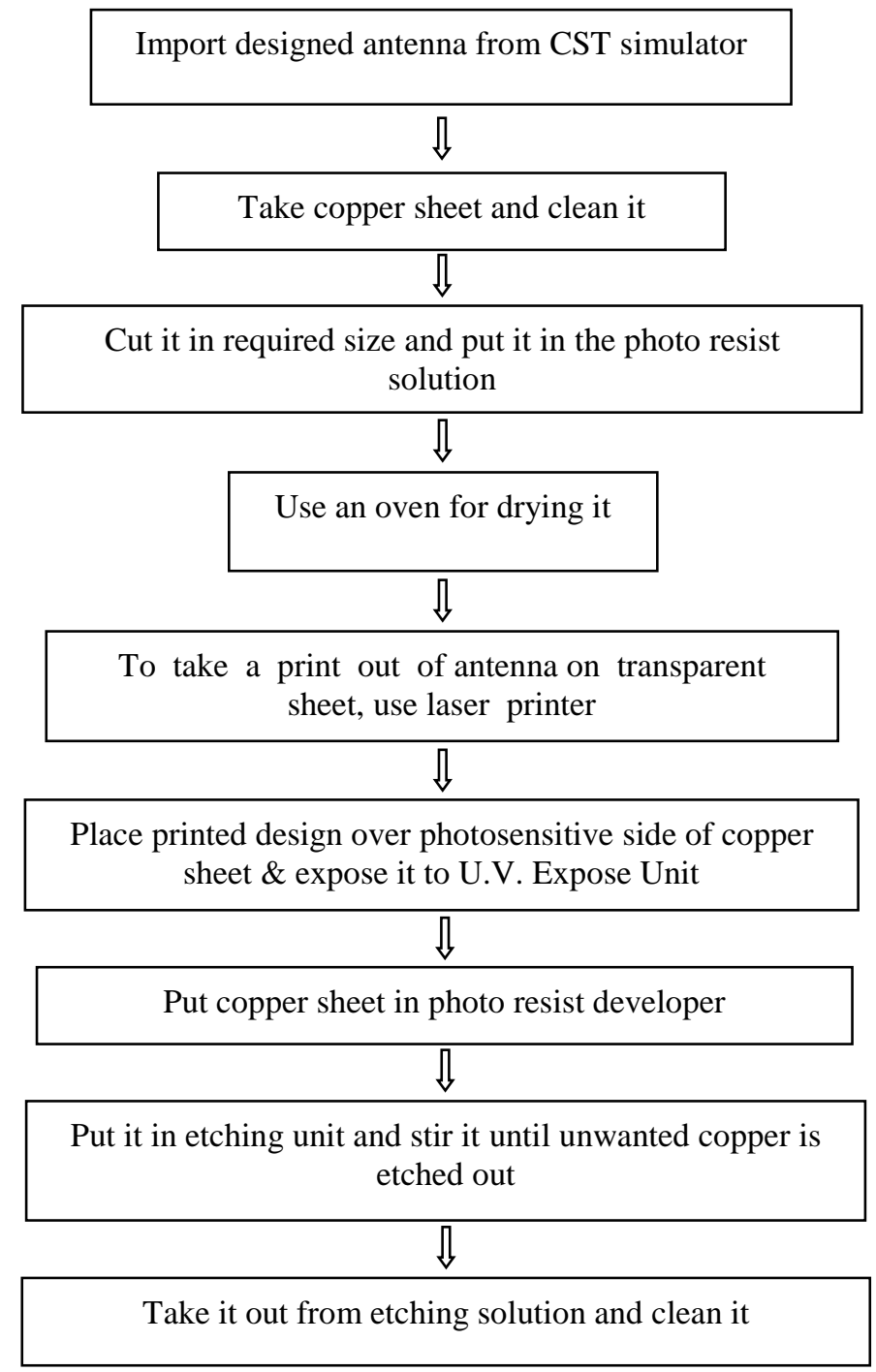

Figure 4 - Flow Chart of the Fabrication Process $[1,10]$ 


\section{Results of the Simulation}

\section{Return Loss}

Return Loss of simulated microstrip patch antenna \& antenna array has been illustrated in Fig.5, 6 and 7 for two patch antennas- P1, P2 without DGS. When the DGS section was not used, the return loss of each of the patch antennas was about $-16 \mathrm{~dB}$ and the mutual coupling between two patch antennas was $-21 \mathrm{~dB}$. But, when the DGS Structure (formed after etching of copper from ground plane) is placed at the ground plane on the substrate, it decreases mutual coupling to upto $-31 \mathrm{~dB} b / w$ patch antennas [2, 4]. The graph for the return loss versus frequency of the designed antenna for patch antennas is shown in figure 5. The more is the negative value of the return loss, the lesser is the mutual coupling $\mathrm{b} / \mathrm{w}$ the patch antenna elements [2, 4,20-26].

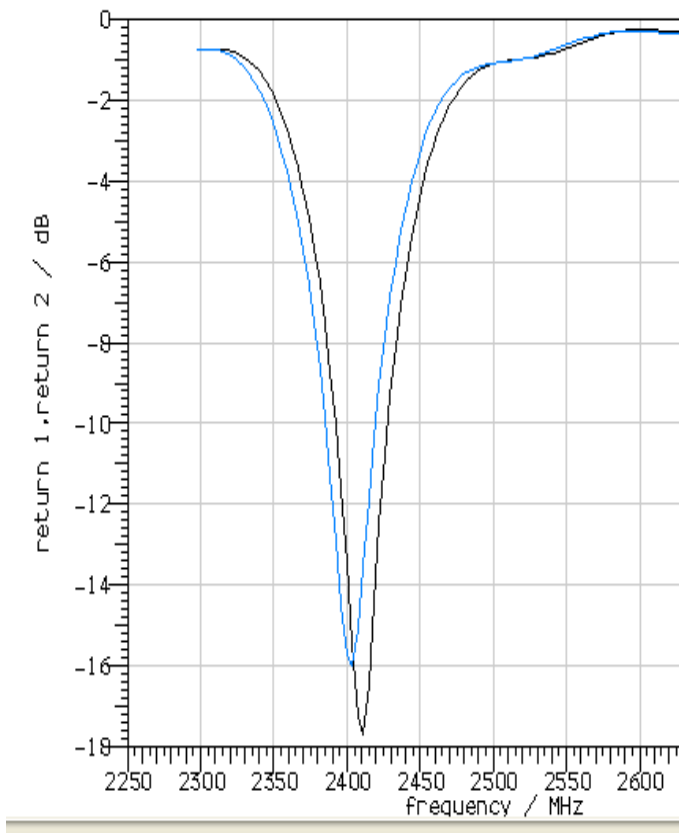

Figure 5 - Return Loss s11 v/s Freq. for two patch antenns- P1, P2 without DGS [1, 2, 4, 11-16]

When the DGS was not used, the graph for the return loss -S11 and S12 $\mathrm{v} / \mathrm{s}$ frequency of the array system for two patch antennas was obtained as using a Sophisticated Non-Linear DGS Structure for High Frequency Wave-Applications. The Law, State and Telecommunications Review, Brasilia, v. 10, n. 1, p. 161-184, May 2018. 
desired, in figure 6 as given below [2, 4]. The curve is somewhat irregular in shape, due to some amount of distortion.

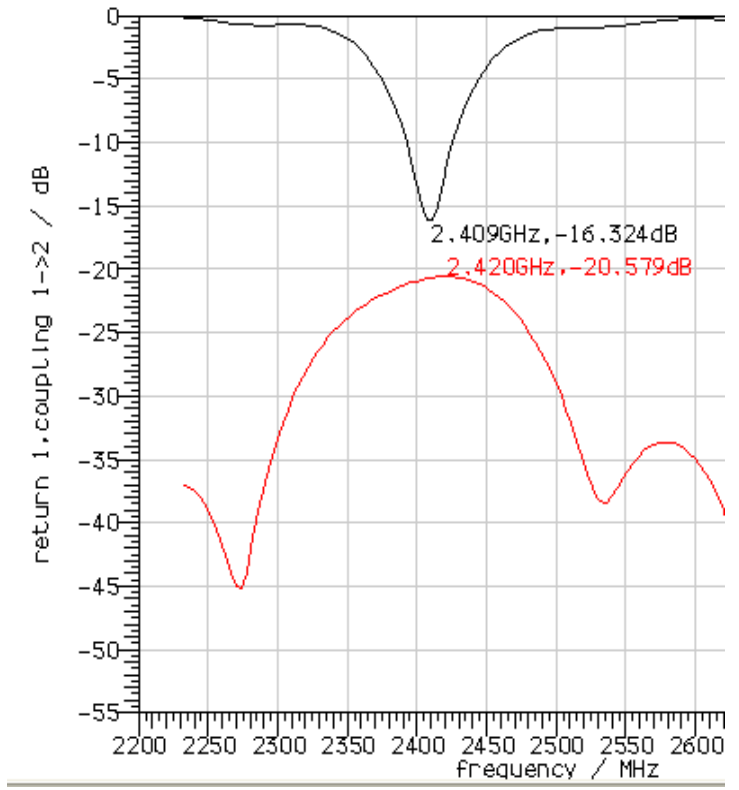

Figure 6 - S11 \& S12 v/s Freq. in absence of DGS for array antenna [1-5, 9-16]

When the DGS was used in the system, the graph for the return loss -S11 and S12 v/s frequency for two patch antennas was obtained as shown below in figure $7[2,4]$. The curve is obtained as desired $[2,4,10]$. 


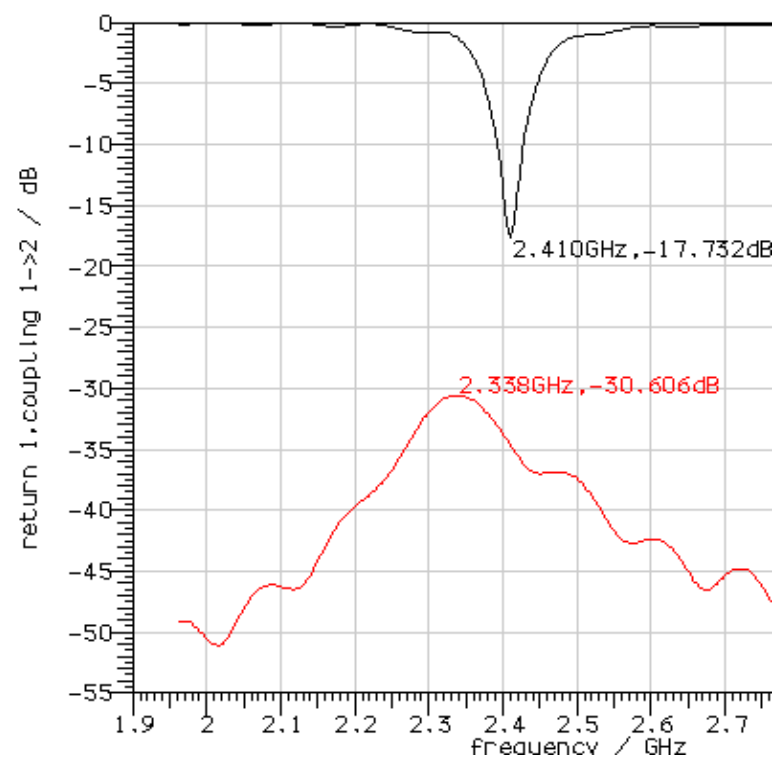

Figure 7 - S11 \& S12 v/s Freq. in presence of DGS for patch array [1, 9, 10, 16-25]

\section{Radiation Pattern}

The radiation pattern of the single band and dual-patch microstrip antenna is shown below in figure 8 . The radiation pattern obtained is bidirectional in nature [1]. 


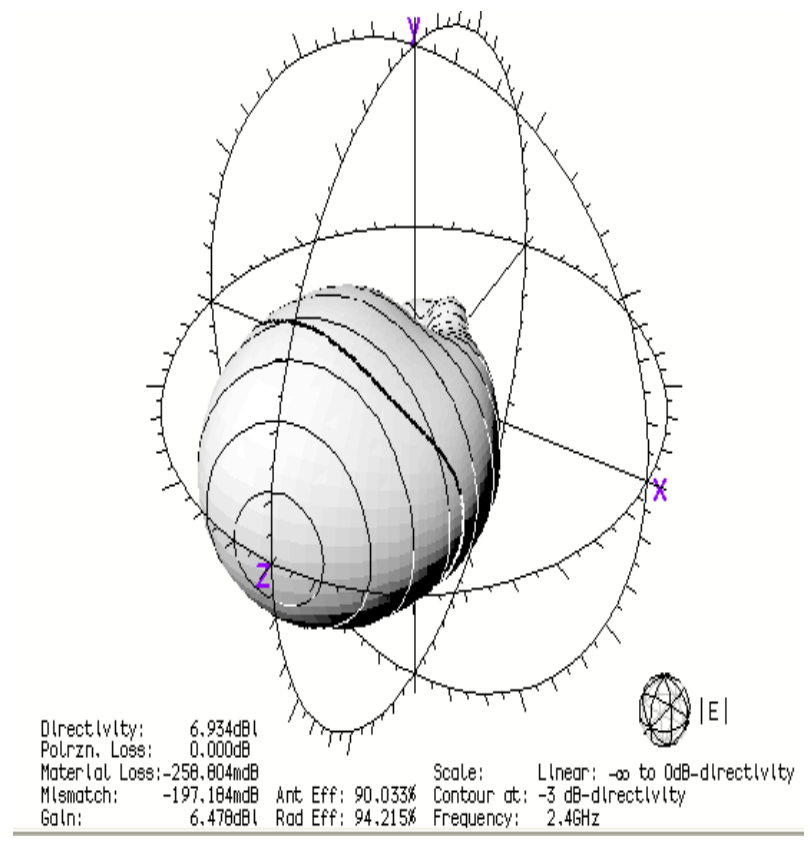

Figure 8 - Radiation Pattern of Patch Antenna [1, 2, 4, 5, 20-25]

\section{Percentage Efficiency of Patch Antenna Array}

The Radiation efficiency of over $94 \%$ is obtained in this work, when the antenna array design is fabricated and simulated through the CST Simulator Software. The measured results confirm the same. The graph for radiation efficiency $\mathrm{v} / \mathrm{s}$ frequency of patch array is shown in figure 9 . 


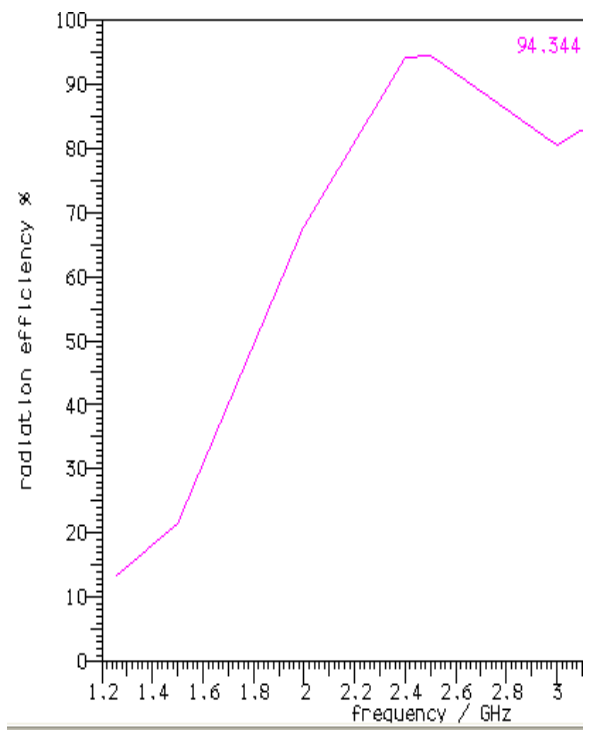

Figure 9 - Radiation Efficiency (in \%) v/s Freq [1, 2, 4, 20-25]

The Antenna efficiency of $90 \%$ is obtained in this work, when the antenna array design is fabricated and simulated through the CST Simulator Software. The graph for the radiation efficiency versus the frequency of the patch antenna array system is shown in figure 10, as given below.

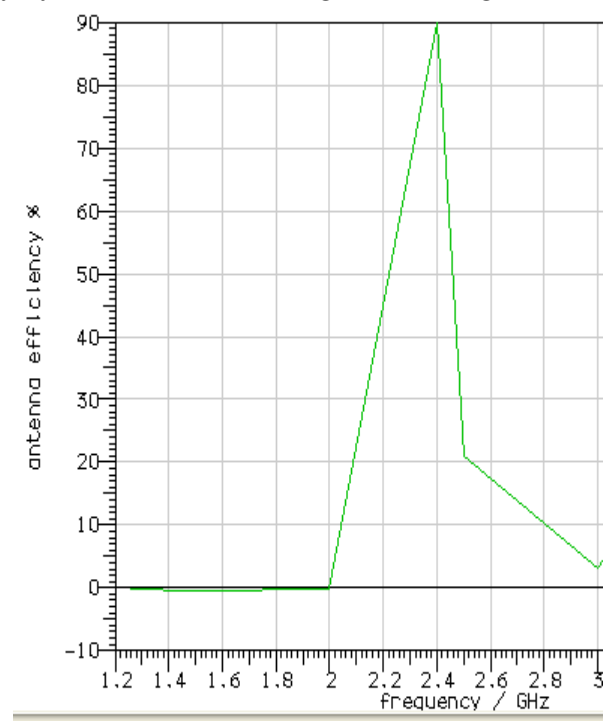

Figure 10 - Antenna Efficiency (in \%) v/s Freq [1, 2, 4, 20-25]

GUPTA, L.; DWIVEDI, A. D. D. Suppression of Mutual Coupling Between Two Microstrip Patch Antennas using a Sophisticated Non-Linear DGS Structure for High Frequency Wave-Applications. The Law, State and Telecommunications Review, Brasilia, v. 10, n. 1, p. 161-184, May 2018.

[DOI: https://doi.org/10.26512/1str.v10i1.21505] 


\section{Mutual Coupling Comparison among two Antennas}

When there was no DGS present, the mutual coupling between the patch antenna elements was high and various observations were obtained, through the antenna simulation software. These observations are given below in Table 2 in the specified manner $[2,4,5,10]$.

\begin{tabular}{|c|c|c|}
\hline $\begin{array}{c}\text { Distance between } \\
\text { two antennas } \\
\text { (In mm.) }\end{array}$ & $\begin{array}{c}\text { Observed Freq. } \\
\text { (In GHZ.) }\end{array}$ & $\begin{array}{c}\text { Mutual Coupling } \\
\text { (In dB) }\end{array}$ \\
\hline 6 & 2.40 & -14.57 \\
\hline 16 & 2.41 & -16.85 \\
\hline 20 & 2.41 & -17.45 \\
\hline 24 & 2.42 & -18.16 \\
\hline 28 & 2.42 & -18.98 \\
\hline 32 & 2.42 & -19.79 \\
\hline 34 & 2.42 & -20.57 \\
\hline
\end{tabular}

Table 2 - Mutual Coupling, when DGS is absent $[4,5,10]$

Now, when DGS is introduced into the array system, mutual coupling between the patch elements is greatly reduced [4]. The following observations are obtained (use of DGS) in the array system, which is shown below in the Table $3[2,10]$.

\begin{tabular}{|c|c|c|}
\hline $\begin{array}{c}\text { Distance between } \\
\text { two antennas } \\
\text { (In mm.) }\end{array}$ & $\begin{array}{c}\text { Observed Freq. } \\
\text { (In GHZ.) }\end{array}$ & $\begin{array}{c}\text { Mutual Coupling } \\
\text { (In dB) }\end{array}$ \\
\hline 6 & 2.40 & -22.13 \\
\hline 16 & 2.35 & -27.50 \\
\hline 20 & 2.35 & -27.87 \\
\hline 24 & 2.34 & -28.83 \\
\hline 28 & 2.34 & -28.87 \\
\hline
\end{tabular}




\begin{tabular}{|c|c|c|}
\hline 32 & 2.34 & -29.60 \\
\hline 34 & 2.34 & -30.60 \\
\hline
\end{tabular}

Table 3 - Mutual Coupling, when DGS is present $[4,5,9,10,14-16]$

On comparison of the results from both tables above, it is quite clear that there is a reduction of $10 \mathrm{~dB}$ in mutual coupling of the two patch antennas having a distance of $34 \mathrm{~mm}$, when the DGS is present in the array system $[2,4,10]$.

\section{Mathematical Modelling}

The expression for the "Effective Permittivity" is given by:

$$
\varepsilon_{e f f}=\frac{1+\varepsilon_{r}}{2}+\frac{\varepsilon_{r}-1}{2}\left(1+\frac{12 h}{W}\right)^{-0.5}
$$

Where, $h=$ Height of dielectric substrate, $\&$

$W=$ Width of the patch, $\mathrm{E}_{\mathrm{r}}=$ relative permittivity of FR-4.

The fringing fields along the width are modelled as radiating slots and electrically, patch of the microstrip antenna looks larger as compared to the physical dimensions. The dimensions of patch along with its length are extended on each end by the distance $\Delta l$, which is given empirically by:

$$
\Delta l=0.412 h\left(\frac{0.262+W / h}{0.814+W / h}\right)\left(\frac{\varepsilon_{\text {eff }}+0.3}{\varepsilon_{\text {eff }}-0.258}\right)
$$

The effective length of the patch $L$ now becomes:

$$
L=\frac{c}{2 f_{r} \sqrt{\varepsilon_{e f f}}}-2 \Delta l
$$

For efficient radiation, the width $W$ is given by:

$$
W=\frac{c}{2 f_{r}}\left(\frac{\varepsilon_{r}+1}{2}\right)^{-0.5}
$$

Where, $\mathrm{f}_{\mathrm{r}}=$ resonance frequency of array antenna.

GUPTA, L.; DWIVEDI, A. D. D. Suppression of Mutual Coupling Between Two Microstrip Patch Antennas using a Sophisticated Non-Linear DGS Structure for High Frequency Wave-Applications. The Law, State and Telecommunications Review, Brasilia, v. 10, n. 1, p. 161-184, May 2018. 


\section{Cavity Model}

The Cavity model is much more complex as compared to the transmission line model and provides more precise results. In it, region between patch and ground surface plane is treated as a cavity, that is surrounded by the magnetic walls around periphery and through the electric walls from top and bottom sides. As thin substrates are used, field inside cavity is assumed to be uniform, along thickness of the dielectric substrate [2]-[8].

In this model, analysis is made simple by expressing electromagnetic fields within patch substrate as the summation of different resonant modes of two-dimensional radiator. As the normal substrates, which are used to produce patch antennas are quite thin, so usual assumption is that, field inside cavity is uniform along thickness of the dielectric substrate [1].

The Cavity model makes following assumptions:

$>$ Since the dielectric substrate is assumed as thin, the fields in the cavity do not vary with the z-axis.

$>$ Tangential component of magnetic field is negligible at edges of the patch.

$>$ Existence of the fringing field can easily be accounted for, by slightly increasing edges of the patches.

\section{Full Wave Solutions- Method of Moments}

The Full wave models are versatile and provide precise results. The Finite Difference Time Domain method and the Finite element method (FEM), all belongs to this category. They are quite suitable for the volumetric configurations. The Finite Element Method is very popular among all these methods. In this method, region of interest is divided into a number of finite surfaces or volume elements, depending upon planar or volumetric-structures to be analysed. These discretized units (finite elements) are well-defined geometrical shapes, like triangular elements for the planar configurations and tetrahedral \& prismatic elements for the three-dimensional configurations. The software used in this study is called CST (Computer Simulation Technology) Antenna Simulation Software [2]-[10].

From field point of view, the important quantitative information on an antenna is its directivity, which is the measure of concentration of the radiated power in the particular direction. It is defined as ratio of radiation intensity in the given direction from an antenna to that of the radiation intensity, averaged over all directions. using a Sophisticated Non-Linear DGS Structure for High Frequency Wave-Applications. The Law, State and Telecommunications Review, Brasilia, v. 10, n. 1, p. 161-184, May 2018. 
Average radiation intensity is equivalent to total radiated power, divided by $4 \pi$. If direction is not specified, then direction of the maximum radiation is implied [1]. Mathematically, "Directivity" (Dn-dimensionless) can be written as:

$$
D_{n}=\frac{U(\theta, \phi)}{U(\theta, \phi)}=\frac{4 \pi U(\theta, \phi)}{P_{t}}=\frac{4 \pi U(\theta, \phi)}{\iint U d \Omega}
$$

Where, $\mathrm{P}_{\mathrm{t}}=$ total radiated power in Watts, \&

$\mathrm{U}=$ radiation intensity in $\mathrm{W} /$ unit solid angle.

It is linked to the average radiated power density- $\mathrm{S}_{\mathrm{av}}\left(\mathrm{W} / \mathrm{m}^{2}\right)$ by:

$$
U=r^{2} S_{a v}
$$

In practical applications, total input power to the antenna can be easily obtained, but actual total radiated power by the antenna has to be find out. Gain of the antenna is introduced to solve this critical problem. This is defined as ratio of radiation intensity in the given direction from antenna, to total input power accepted by antenna, divided by $4 \pi$. If direction is not specified, then direction of the maximum radiation is implied [1]. Mathematically, the gain (dimensionless) can be written as:

$$
G=\frac{4 \pi U}{P_{i n}}
$$

Where, $\mathrm{U}=$ radiation intensity in $\mathrm{W} /$ unit solid angle, \&

$\mathrm{P}_{\mathrm{in}}=$ total input power accepted by antenna in Watts.

The input power can be different from input power accepted by antenna, when the feed line is not matched with antenna. Basically, feed line is matched with the patch antenna and matching efficiency is $100 \%$. The "Gain" is linked to the "Directivity" $\left(\mathrm{D}_{0}\right)$ by the following relation:

$$
G=\frac{P_{t}}{P_{i n}} D_{o}=\eta_{o} D_{o}
$$

Now, ' $\eta_{\mathrm{e}}$ ' is defined as the radiation efficiency factor of antenna and is the ratio of radiated power to the input power, accepted by antenna. It is given by: 


$$
\eta_{e}=\frac{P_{t}}{P_{i n}}
$$

This efficiency factor has taken both, the conductor loss and dielectric loss, into its consideration.

Radiation pattern contains useful information about radiation characteristics of the antenna, where some cannot be qualified (shape of pattern) and some can be qualified. The half power beam width (HPBW) of main lobe is also called 3-dB beam width or simply beam width. The antenna polarization is same as that of the polarization of its radiating wave. Most of the mobile phone antennas are not purely linearly polarized, since the antennas are employed to receive the signals with mixed polarization values. Orthogonally polarized antennas cannot exchange information with each other, due to polarization mismatch across them [10]-[15].

The bandwidth of an antenna can be defined in terms of one or more physical parameters. The bandwidth is calculated by using the frequencies $f_{u}$ and $f_{1}$ at the upper and lower edges of the achieved bandwidth respectively. The bandwidth of an antenna is given by [1], [15]:

$$
B W=\frac{V S W R-1}{Q \sqrt{V S W R}}
$$

Where, VSWR = Voltage-standing-wave-ratio.

For maximum power transfer phenomenon, return loss should have the smallest possible value [1]. This means that ratio $\mathrm{P}_{\mathrm{R}} / \mathrm{P}_{\mathrm{T}}$ must be as small as possible. When expressed in decibels $(\mathrm{dB})$, the return loss should be a large negative number as possible. It is defined empirically through the following relation, which is given by [1]-[5]:

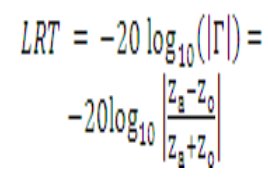

Where, $\Gamma=$ reflection signals at feed point of antenna, $\mathrm{Z}_{\mathrm{a}}=$ input impedance of antenna, $\mathrm{LRT}=$ return-loss, \& $Z_{\mathrm{o}}=$ characteristic impedance of the feed line.

Also, $\operatorname{VSWR}=\left(\mathbf{Z}_{\mathrm{L}}-\mathbf{Z}_{0}\right) /\left(\mathbf{Z}_{\mathrm{L}}+\mathbf{Z}_{0}\right)$ using a Sophisticated Non-Linear DGS Structure for High Frequency Wave-Applications. The Law, State and Telecommunications Review, Brasilia, v. 10, n. 1, p. 161-184, May 2018. 
Where, $\mathrm{Z}_{\mathrm{L}}=$ Load Impedance, \&

$\mathrm{Z}_{0}=$ Characteristic Impedance of the feed line.

\section{Results after Testing Through V.N.A.}

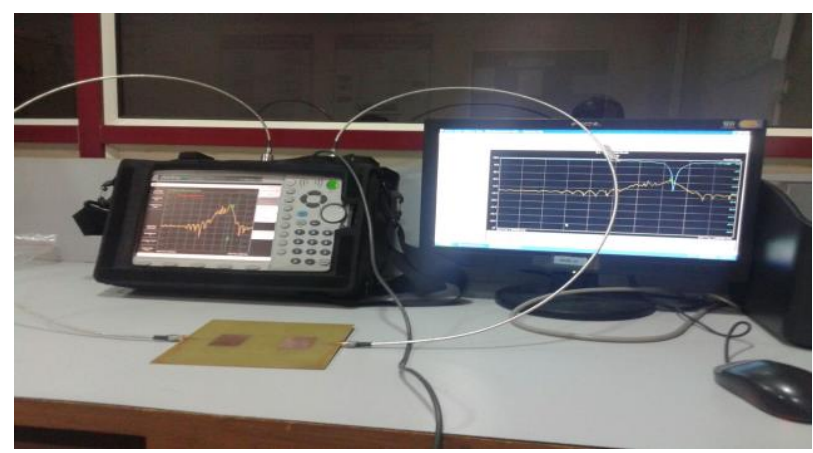

Figure 11 - Experimental set up of V.N.A.

The range of the measurement setup is approximately between 1-7 Ghz. The model of Vector network analyzer is MS 2028C. The setup is manufactured by the Anritsu Company and made in U.S.A. The proposed antenna is connected to the $6 \mathrm{dBi}$ power divider through the Vector network analyzer signal generator port. The response of the proposed microstrip patch antenna has been shown on the screen, as shown in the above figure.

\begin{tabular}{|c|c|c|c|}
\hline S.NO. & Parameter & $\begin{array}{c}\text { CST } \\
\text { Simulation } \\
\text { Results }\end{array}$ & $\begin{array}{c}\text { V.N.A. } \\
\text { Measured } \\
\text { Results }\end{array}$ \\
\hline 1. & Return Loss & $-20.57 \mathrm{~dB}$ & $-22.96 \mathrm{~dB}$ \\
\hline 2. & Res. Freq. & $2.42 \mathrm{GHz}$ & $2.47 \mathrm{GHz}$ \\
\hline
\end{tabular}

Table 4 - Comparison of Results obtained from CST Simulator and V.N.A. 


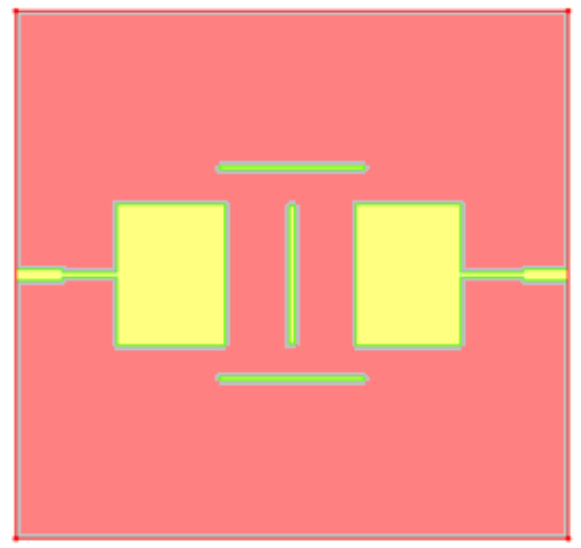

Figure 12 - Edge View of Microstrip antenna model with DGS.

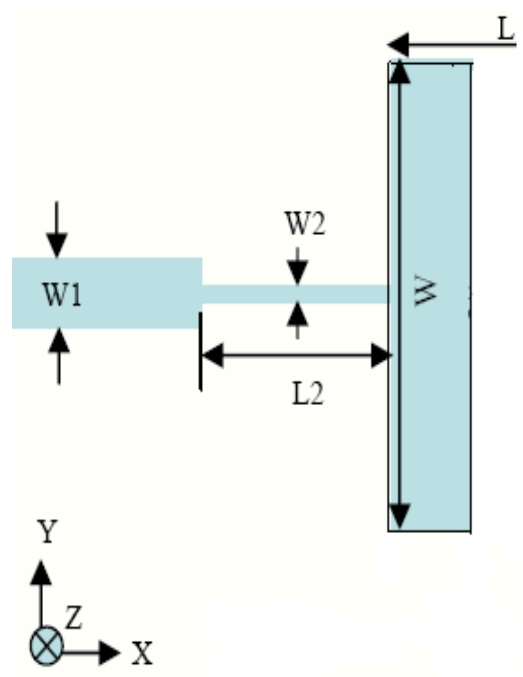

Figure 13 - Labeled Model for single microstrip patch antenna. using a Sophisticated Non-Linear DGS Structure for High Frequency Wave-Applications. The Law, State and Telecommunications Review, Brasilia, v. 10, n. 1, p. 161-184, May 2018.

[DOI: https://doi.org/10.26512/1str.v10i1.21505] 


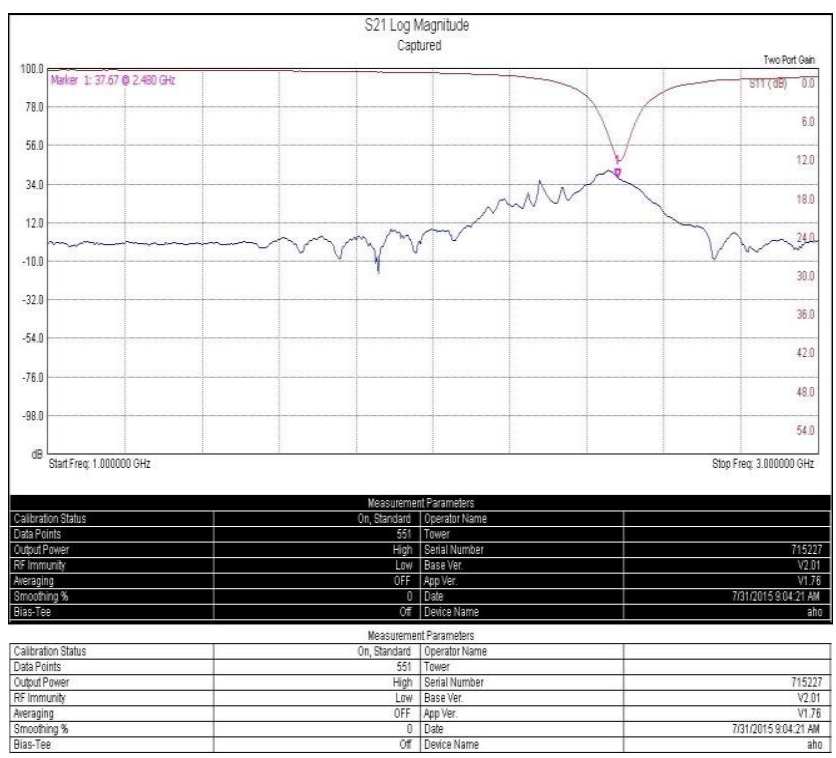

Figure 14 - Measured return loss of the antenna (with D.G.S.)

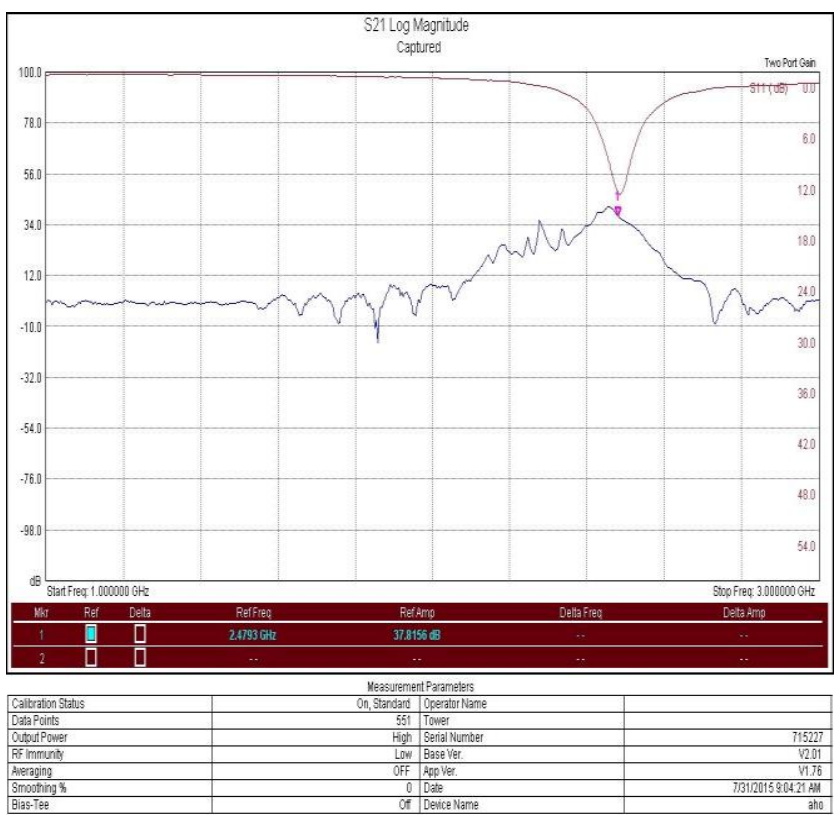

Figure 15 - Measured return loss of the antenna (with D.G.S.)

GUPTA, L.; DWIVEDI, A. D. D. Suppression of Mutual Coupling Between Two Microstrip Patch Antennas using a Sophisticated Non-Linear DGS Structure for High Frequency Wave-Applications. The Law, State and Telecommunications Review, Brasilia, v. 10, n. 1, p. 161-184, May 2018.

[DOI: https://doi.org/10.26512/lstr.v10i1.21505] 


\begin{tabular}{|c|c|c|c|}
\hline S.No. & Parameter & $\begin{array}{c}\text { Simulated results using } \\
\text { CST Simulator }\end{array}$ & $\begin{array}{c}\text { Measured } \\
\text { results by } \\
\text { V.N.A. }\end{array}$ \\
\hline 1. & Return Loss & $-30.6 \mathrm{~dB}$ & $-37.67 \mathrm{~dB}$ \\
\hline 2. & Res. Freq. & $2.34 \mathrm{GHz}$ & $2.48 \mathrm{GHz}$ \\
\hline
\end{tabular}

Table 5 - Comparison of Simulated and Measured Results by V.N.A. (with DGS)

There are no exact reasons for the differing of simulated and measured results, but some possible reasons are given below, which produces this difference in the two readings of the V.N.A. \& CST Antenna Simulator:

$>$ The material used for the fabrication of the proposed antenna.

Assuming that in an ideal environment, simulation setup for the loss tangent of the substrate is set as zero, whereas in real life, loss tangent exists. A greater loss tangent will degrade the performance of the antenna.

$>$ Due to cable loss, noise production by setup and connector loss etc.

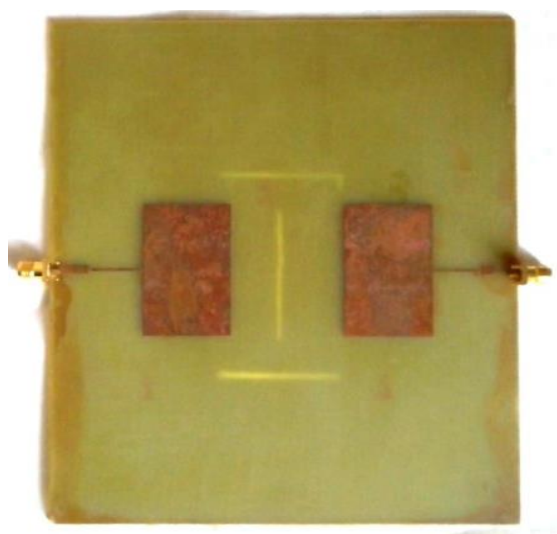

Figure 16 - Photograph of the fabricated patch antenna. 


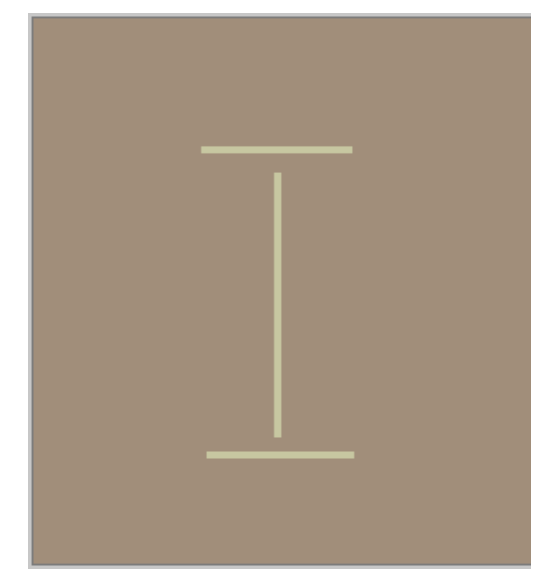

Figure 17 - Photograph of the fabricated patch antenna.

\section{Conclusion}

Mutual coupling between two microstrip patch elements has been studied carefully in this research work. We have observed that proposed system is providing the solution to decrease mutual coupling between two microstrip patch antennas. In this work, we are providing prevention mechanism to decrease interference among the two patches.

A Defected Ground Structure (DGS) has been inserted into the ground plane, under the microstrip patch antenna elements, to reduce the coupling between them. In the radiation pattern of the Patch Antenna Array, the antenna efficiency of greater than $90 \%$ and the radiation efficiency of more than $94 \%$ have been achieved [13].

In this work, the I-shaped DGS structure is placed at back of the dielectric substrate at the ground plane \& mutual coupling has been successfully suppressed. After placement of DGS, the mutual coupling has been greatly reduced. The proposed antenna array is simulated by using the CST Full Wave Electromagnetic Simulator. Also, the prototype has been fabricated and the results are checked through Vector-network-analyzer. Both the simulated and measured results are in very good agreement to each other. After using DGS, the coupling has been reduced from $-22 \mathrm{~dB}$ to $-37 \mathrm{~dB}$. 


\section{Future Work}

The presented research work has been performed over CST Antenna Simulator to reduce mutual coupling between patch antenna array. This proposed work can be enhanced in different ways. These ways are discussed below:

- We can implement this approach over other Simulation Software like HFSS \& can increase the number of patch antennas used in the array. The patch antennas can be fed by a single power source, in place of feeding both the patch antennas individually.

- We can change the frequency of patch elements as well as shape of the DGS to enhance the work in a different way.

- We can use some other transmission line methods, instead of quarter wave transformers, for fulfilling concept of impedance matching between input feed line and microstrip patch array elements.

\section{ACKNOWLEDGEMENT}

The Author Mr. Lavesh Gupta would like to thank Dr. Arun Dev Dhar Dwivedi, Professor in Department of Electrical and Electronics Engineering, Poornima University \& Dr. Mahesh Bundele, Dean R \& D Poornima University, Jaipur, India for providing the necessary guidance and support, during the execution \& completion of this research work.

\section{References}

[1] Constantine A. Balanis, "Antenna Theory, Analysis and Design", ISBN 978-81-265-2422-8, 2nd Edition, John Wiley \& Sons, New York, 2005.

[2] Yu, Yantao, Lijun Yi, Xiaoya Liu, Zhaokai Gu, and Jinghe Li. "Mutual coupling reduction of dual-frequency patch antennas using a simple microstrip H-Section." In 2015 IEEE International Symposium on Antennas and Propagation \& USNC/URSI National Radio Science Meeting, pp. 388389. IEEE, 2015.

[3] Yazdi, Shirin Ramezanzadeh, Somayye Chamaani, and Seyed Arash Ahmadi. "Mutual coupling reduction in microstrip phased array using stacked-patch reduced surface wave antenna." In 2015 IEEE International Symposium on Antennas and Propagation \& USNC/URSI National Radio Science Meeting, pp. 436-437. IEEE, 2015.

[4] Acharjee, Juin, Kaushik Mandal, Sujit Kumar Mandal, and Partha Pratim Sarkar. "Mutual coupling reduction between microstrip patch antennas by using a string of H-shaped DGS." In Microelectronics, Computing and 
Communications (MicroCom), 2016 International Conference on, pp. 1-3. IEEE, 2016.

[5] Hajilou, Y., H. R. Hassani, and B. Rahmati. "Mutual coupling reduction between microstrip patch antennas." In 2012, 6th European Conference on Antennas and Propagation (EUCAP), pp. 1-4. IEEE, 2012.

[6] Emamimeybodi, Seyed Mohammad, and Homayoon Oraizi. "Mutual coupling reduction in microstrip patch antenna array by using planar EBG structure in X band." In 2013, 21st Iranian Conference on Electrical Engineering (ICEE), pp. 1-5. IEEE, 2013.

[7] Singh, G., and J. Kaur. "Design a multiband rectangular ring antenna using DGS for WLAN, WiMAX applications." International Journal of Advance Research in Computer \& Communication Engineering, vol. 3, no. 6, June 2014.

[8] Alayesh, Mahmoud A., Christos G. Christodoulou, Miroslav Joler, and Silvio E. Barbin. "Reconfigurable multi-band stacked Microstrip Patch Antenna for wireless applications." In Antennas and Propagation Conference, 2008. LAPC 2008. Loughborough, pp. 329-332. IEEE, 2008.

[9] Farsi, Saeed, Hadi Aliakbarian, Dominique Schreurs, Bart Nauwelaers, and Guy AE Vandenbosch. "Mutual coupling reduction between planar antennas by using a simple microstrip U-section." IEEE antennas and wireless propagation letters 11 (2012): 1501-1503.

[10] Hazra, Rajasree, Chandan Kumar Ghosh, and S. K. Parui. "Mutual coupling reduction between closely spaced Microstrip patch elements using DGS."Journal of Academia and Industrial Research (JAIR) 2, no. 2 (2013): 142.

[11] Bait-Suwailam, Mohammed M., Omar F. Siddiqui, and Omar M. Ramahi. "Mutual coupling reduction between microstrip patch antennas using slotted-complementary split ring resonators." IEEE Antennas and Wireless Propagation Letters 9 (2010): 876-878.

[12] Chung, Younkyu, Seong-Sik Jeon, Dal Ahn, Jae-Ick Choi, and Tatsuo Itoh. "High isolation dual-polarized patch antenna using integrated defected ground structure." IEEE Microwave and Wireless Components Letters 14, no. 1 (2004): 4-6.

[13] Mouffok, Lila, Lana Damaj, Xavier Begaud, Anne-Claire Lepage, and Hubert Diez. "Mutual coupling reduction between dual polarized microstrip patch antennas using compact spiral artificial magnetic conductor." In Proceedings of the 5th European Conference on Antennas and Propagation (EUCAP), pp. 909-912. IEEE, 2011.

[14] Arya, Ashwini K., M. V. Kartikeyan, and A. Patnaik. "Efficiency enhancement of microstrip patch antenna with defected ground structure." In Recent Advances in Microwave Theory and Applications, 2008. MICROWAVE 2008. International Conference on, pp. 729-731. IEEE, 2008. 
[15] Hammoodi, Ali I., Hussain M. Al-Rizzo, and Ayman A. Isaac. "Mutual coupling reduction between two monopole antennas using fractal based DGS." In 2015 IEEE International Symposium on Antennas and Propagation \& USNC/URSI National Radio Science Meeting, pp. 416-417. IEEE, 2015.

[16] Kumar, Ajay, Dwejendra Arya, and D. K. Srivastava. "Band width of microstrip antenna improved by using mushroom type EBG structure." In Multimedia, Signal Processing and Communication Technologies (IMPACT), 2013 International Conference on, pp. 159-162. IEEE, 2013.

[17] Yu, Yantao, Lijun Yi, Xiaoya Liu, and Zhaokai Gu. "Mutual coupling reduction of dual-frequency MIMO array with neutralization lines." In 2015 Asia-Pacific Microwave Conference (APMC), vol. 1, pp. 1-3. IEEE, 2015.

[18] Farahani, Hossein Sarbandi, Mehdi Veysi, Manouchehr Kamyab, and Alireza Tadjalli. "Mutual coupling reduction in patch antenna arrays using a UC-EBG superstrate." IEEE Antennas and Wireless Propagation Letters 9 (2010): 57-59.

[19] Yang, Xin Mi, Xue Guan Liu, Xiao Yang Zhou, and Tie Jun Cui. "Reduction of Mutual Coupling Between Closely Packed Patch Antennas Using Waveguided Metamaterials." IEEE Antennas and Wireless Propagation Letters 11 (2012): 389-391.

[20] Hamideh Kondori, Mohammad Ali Mansouri-Birjandi and Saeed Tavakoli, "Reducing Mutual Coupling in Microstrip Array Antenna Using Metamaterial Spiral Resonator", IJCSI International Journal of Computer Science Issues, vol.-9, issue-3, no.-1, May 2012.

[21] R. Garg, P. Bhartia, I. Bahl and A. Ittipiboon, "Microstrip Antenna Design Handbook", ISBN 0-89006-513-6, $2^{\text {nd }}$ Edition, Artech House, 2000.

[22] Girish kumar and K. P. Ray, "Broadband Microstrip Antennas", ISBN 158053-244-6, $1^{\text {st }}$ Edition, Artech House, 2003.

[23] Thomas A. Milligan, “ Modern Antenna design”, 2nd Edition, John Wiley \& Sons, 2005.

[24] Prasad, K. D., and Deepak Handa. Antenna and wave propagation. Satya Prakashan, 2003

[25] Kraus, John D., Ronald J. Marhefka, and Ahmad S. Khan. Antennas and wave propagation. Tata McGraw-Hill Education, 2006.

[26] Gupta, L. \& Dwivedi, A.D.D. J Comput Electron (2017). https://doi.org/10.1007/s10825-017-1088-2. 